\title{
Surface Layers at the Polarized Liquid/Liquid Interfaces
}

\author{
Vladimír Mareček
}

Received March 25, 2014

\begin{abstract}
Approaches to the formation of a dense and stable surface layer at the polarized liquid/liquid interface affecting the selectivity of the interfacial ion transfer are considered. Three examples of the preparation of such surface layers, including the silicate membrane, the ion-pair stabilized phospholipid film, and a polymer surface layer, are discussed. Relevance of studies in this area to modeling of the biological and technological membrane processes is highlighted.
\end{abstract}

Keywords: Polarized liquid/liquid interface; Ion transfer; Adsorption; Surface layer; Membrane; Applications

\section{Introduction}

The formation of surface layers at the polarized liquid/liquid interface, also referred to as the interface between two immiscible electrolyte solutions (ITIES), offers a tool enabling to regulate the selectivity of the interfacial ion transfer, which could be important in modeling of biological or technological membrane processes. The most important step here is the formation of an adsorbed monolayer. It has been shown that such monolayer can hardly be sufficiently dense and stable to influence the ion transfer reaction. There are at least two ways how to increase the stability and density of the adsorbed layer. The first one relies on a chemical reaction in which the adsorbed ionic surfactant forms an associate or complex with ions present in the opposite phase. The second one is based on the polymerization within the adsorbed monolayer, which leads to the creation of a chemical bond between the adsorbed molecules. Typical examples of the former approach include the preparation of a silicate membrane at the ITIES, and the stabilization of the phospholipid monolayer in the presence of multiply charged cations in the aqueous phase. An example of the latter approach is the preparation of a polymer layer from surface active derivatives of pyrrole. The above-mentioned examples of the preparation of surface layers and their properties will be discussed in this paper.

\section{Preparation of a silicate membrane}

One of the most common approaches to the preparation of thin porous materials and membranes is application of the sol-gel technology [1]. The synthesis usually starts in a single solution containing all the components.

J. Heyrovský Institute of Physical Chemistry, Academy of Sciences of the Czech Republic, Dolejškova 3, 18223 Prague 8, Czech Republic. E-mail: vladimir.marecek@jh-inst.cas.cz. 
Formation of a gel phase and its condensation are achieved by slowly changing the experimental conditions such as the solution $\mathrm{pH}$ or temperature. Polycrystalline films have been grown on various supports, and tetraalkylammonium cations have been often used in the sol-gel processing as the templates $[2,3]$. The number of the carbon atoms in the alkyl chain has been usually smaller than four. The negative charge on the precursor anion is then compensated through the association with the positively charged template ion, thus enabling their aggregation and chaining. A very interesting and powerful modification of the classical sol-gel method including only the single-phase operations has emerged from the polarization studies at the ITIES (see, e.g., [4]). Its principal idea consists in the separation of the template and precursor ions participating in sol-gel processes by the liquid/liquid interface [5]. The sol-gel process is initiated by the potential-controlled adsorption of the template ions followed by their transfer from the organic solvent to the aqueous phase. The association of the positive template ions with the silicate ions at the aqueous side of the interface produces neutral species, which accumulate and form a compact layer.

When the template and the precursor are separated by the liquid/liquid interface, it is possible to control very finely the transport of the components to (or across) the interface by varying the interfacial potential difference, and thus to modify the properties of the formed porous film. This adds another dimension to the classical sol-gel processes, which can only be controlled by varying the experimental conditions in a single phase.

The overall reaction for the formation of a solid phase(s) at the ITIES could be described as [5]

$$
\begin{aligned}
& 4 \mathrm{TODA}^{+}(\mathrm{o})+\mathrm{Si}_{4} \mathrm{O}_{8}(\mathrm{OH})_{4}{ }^{4-}(\mathrm{w}) \leftrightarrows \\
& \mathrm{TODA}_{4} \mathrm{Si}_{4} \mathrm{O}_{8}(\mathrm{OH})_{4}(\mathrm{~s})
\end{aligned}
$$

where $\mathrm{TODA}^{+}$is the template ion dissolved in the organic phase in the form of trimethyloctadecylammonium tetraphenylborate (TODATPB), and the precursor silicate ions (diluted water glass) are present in the aqueous phase. This reaction scheme has been confirmed by the surface tension measurements (Fig. 1) [6]. As it can be seen from Fig. 1, the surface tension decreases at potentials below $0.4 \mathrm{~V}$, when $1 \mathrm{mM}$ $\mathrm{TODA}^{+}$is added to the system containing 0.045 $\mathrm{M} \mathrm{SiO}_{2}$ in the aqueous phase (Fig. 1, curve c). In the absence of $\mathrm{TODA}^{+}$in the organic phase, the surface tension only exhibits a constant decrease (Fig. 1, curve b) from the value obtained in the presence of the base electrolytes (Fig. 1, curve a), i.e., $5 \mathrm{mM}$ tetraphenylarsonium 3,3'-comobis(undecahydro-1,2-dicarba-3-cobalta-closododecabor)-ate (TPAsDCC) in 1,2-DCE and 5 $\mathrm{mM} \mathrm{NaCl}$ in water [6].

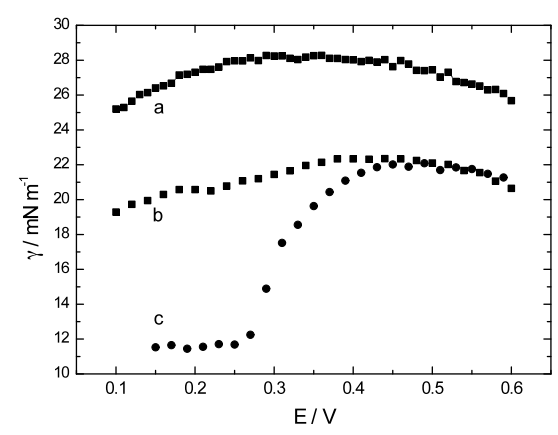

Fig. 1. Surface tension of the water|1,2-DCE interface in the presence of (a) $5 \mathrm{mM} \mathrm{NaCl}(\mathrm{w})$ and $5 \mathrm{mM}$ TPAsDCC(o); (b) ad (a) $+0.045 \mathrm{M}$ $\mathrm{SiO}_{2}(\mathrm{w})$; (c) ad (b) + 1 mM TODATPB(o). 
The formation of an adsorbed layer can be also demonstrated by the cyclic voltammograms measured at higher scan rates, cf. Fig. 2. At a scan rate of $50 \mathrm{mV} \mathrm{s}^{-1}$, a small pre-wave corresponding to an adsorbed monolayer formation appears at a potential of $0.23 \mathrm{~V}$ in the presence of both $\mathrm{TODA}^{+}$and water glass. The formation of a silicate layer proceeds further at lower potentials generating a current peak at $0.13 \mathrm{~V}$, whose potential shifts with increasing scan rate. However, the potential of the reverse current peak is constant and corresponds to the adsorption potential of TODA ${ }^{+}$. This behavior suggests that the reverse process is controlled by the desorption of $\mathrm{TODA}^{+}$from the interfacial silicate layer. (For the purpose of the conversion of the applied voltage to the interfacial potential difference, the voltammograms were recorded in the presence of a small amount of TMACl in the aqueous phase).

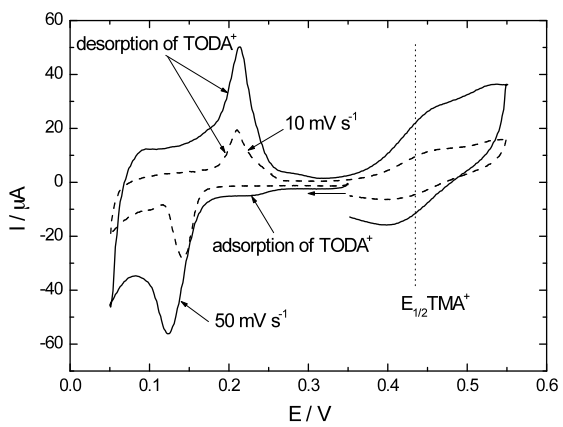

Fig. 2. Cyclic voltammograms recorded in the presence of $5 \mathrm{mM} \mathrm{NaCl}, 10 \mathrm{mM} \mathrm{SiO}_{2}$ and 0.5 $\mathrm{mM}$ TMACl in the aqueous phase and $5 \mathrm{mM}$ TODATPB in the organic phase. Area of the interface is $20 \mathrm{~mm}^{2}$.

Similar reactions of $\mathrm{TODA}^{+}$at the liquid/liquid interface can also be observed in the presence of several other multiply charged anions, such as $\mathrm{B}_{4} \mathrm{O}_{7}{ }^{2-}, \mathrm{Fe}(\mathrm{CN})_{6}{ }^{3-}$ or $\mathrm{Fe}(\mathrm{CN})_{6}{ }^{4}$ in the aqueous phase. Depending on the anion, either a multilayer grows at the interface, or only an adsorbed monolayer is formed, which is followed by a facilitated transfer reaction. While multivalent bulky anions, e.g., silicates, ferroand ferricyanides, give rise to multilayers, in the presence of the smaller $\mathrm{PtCl}_{4}{ }^{2-}$ anion the latter mechanism applies. These reactions can be utilized for the preparation of the composite layers, or for the doping of the silicate layers with other ions.

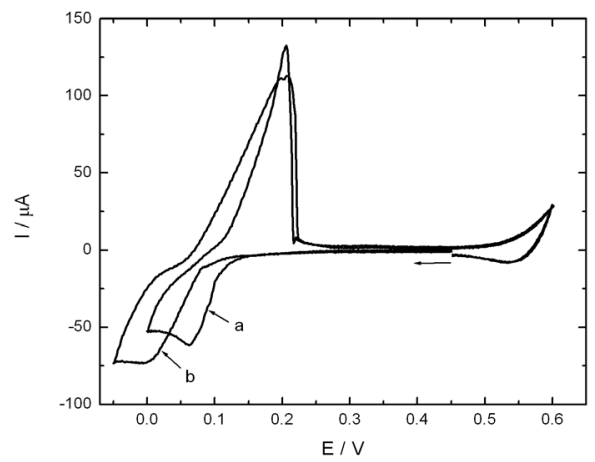

Fig. 3. Cyclic voltammograms recorded in the presence of $5 \mathrm{mM} \mathrm{NaCl}$ and $0.3 \mathrm{mM}$ : (a) $\mathrm{K}_{3}\left[\mathrm{Fe}(\mathrm{CN})_{6}\right]$; (b) $\mathrm{K}_{4}\left[\mathrm{Fe}(\mathrm{CN})_{6}\right]$ in the aqueous phase and $5 \mathrm{mM}$ TODATPB in the organic phase. The polarization rate, $v=50 \mathrm{mV} \mathrm{s}^{-1}$. Area of the interface, $20 \mathrm{~mm}^{2}$.

Cyclic voltammograms of the surface layer formation, which were recorded in the presence of ferro- or ferricyanides anions in the aqueous phase, are shown in Fig. 3. It can be seen that for anions with a higher charge (curve b) the negative current peak is larger and shifts to more negative potentials, thus demonstrating effect of the precursor ion charge on the layer formation. Similar effect was observed when the chemical composition of the water glass solution was changed by changing the solution $\mathrm{pH}$. 


\section{Preparation of a stable phospholipid film}

The behavior and properties of the phospholipid films formed by L- $\alpha$-lecithin (DPPC) at the water/organic solvent interfaces have been recently studied electrochemically using the weakly acidified aqueous electrolyte solutions [9]. In the presence of an acid, the polar phosphate heads of the adsorbed DPPC protruding into the aqueous phase are protonated. Unlike its zwitterionic form, the protonated form of DPPC can desorb from the interface at the positive potentials where aqueous side of the interface becomes positively charged. On the other hand, the film of the protonated phospholipids can be stabilized through the formation of ion pairs with the aqueous anion. In contrast to the zwitterionic or protonated forms of the adsorbed phospholipid, its ion-pair form evidently inhibits the ion transfer across the liquid/liquid interface [7,8]. A typical example of the ion-pair effect is an increased stability and density of the phospholipid layer formed in the presence of the multiply charged anions, e.g., $\mathrm{Ce}\left(\mathrm{SO}_{4}\right)_{3}{ }^{2-}$ in the aqueous phase [8].

The mechanism of the DPPC adsorption/ desorption at the ITIES has been proposed to follow the scheme [9]:

$$
\begin{array}{ccc}
1 & 2 & 3 \\
\mathrm{~L}^{ \pm}{ }_{(\mathrm{o})} \leftrightarrows \mathrm{L}^{ \pm}{ }_{(\mathrm{ad})}+\mathrm{H}_{(\mathrm{w})}^{+} \leftrightarrows \mathrm{HL}_{(\mathrm{ad})}^{+} \leftrightarrows \mathrm{HL}_{(\mathrm{o})}^{+}
\end{array}
$$

In the first step, the DPPC zwitterion $\mathrm{L}^{ \pm}$present in the organic phase (o) is adsorbed at the interface attaining the adsorption steady state or equilibrium. Subsequently, it undergoes an acid-base interaction with the hydrogen ions present in the aqueous phase (w), which leads to a steady state or even an equilibrium in the adsorbed state (step 2). The protonated form attains an adsorption/desorption steady state or equilibrium in step 3 .

It has been supposed that the multiple charged cations like $\mathrm{Ce}^{4+}$ interact with the phosphate group of the adsorbed phospholipids [7]. However, in the presence of a high concentration of sulfuric acid required to dissolve $\mathrm{Ce}^{4+}$ in the aqueous phase, the phosphate group of the adsorbed phospholipid will be protonated (step 2 in mechanism (2)), and the $\mathrm{Ce}^{4+}$ cation will be present mostly in the form of its negatively charged sulfate complexes, e.g., $\mathrm{Ce}\left(\mathrm{SO}_{4}\right)_{3}{ }^{2-}$. In this case, the results point to the formation of ion pairs between the protonated phospholipids and the negatively charged complex $\mathrm{Ce}\left(\mathrm{SO}_{4}\right)_{3}{ }^{2-}[8]$ :

$2 \mathrm{HL}^{+}{ }_{(\mathrm{ad})}+\mathrm{Ce}\left(\mathrm{SO}_{4}\right)_{3}{ }^{2-}{ }_{(\mathrm{w})} \leftrightarrows(\mathrm{HL})_{2} \mathrm{Ce}\left(\mathrm{SO}_{4}\right)_{3(\mathrm{ad})}$

This reaction is more likely to occur than the reaction of $\mathrm{Ce}^{4+}$ with the phosphate group of the adsorbed phospholipids. $\mathrm{HL}^{+}{ }_{\text {(ad) }}$ consumed in the reaction (3) has to be replenished to maintain the acid-base equilibrium, (step 2 in mechanism (2)), which results in a higher density of the adsorbed layer.

The ion pair effect is demonstrated in Fig. 4, which shows the voltammetric behavior of a DPPC layer in the absence (curve a) and presence (curve b) of cerium(IV) sulfate in the aqueous phase. The DPPC desorption peak, which is small and flat in the absence of cerium(IV) sulfate, becomes well-pronounced and sharp on addition of this salt to the aqueous phase. When the polarization rate is increased from $0.02 \mathrm{~V} \mathrm{~s}^{-1}$ to $0.24 \mathrm{~V} \mathrm{~s}^{-1}$, the desorption peak shifts by $45 \mathrm{mV}$ toward the more positive values. The DPPC desorption is a charging 
process and, therefore, the peak current is directly proportional to the polarization rate. The desorption peak height increases and the peak shifts toward more positive potentials with increasing the time delay at the initial potential, at which the DPPC layer is formed.

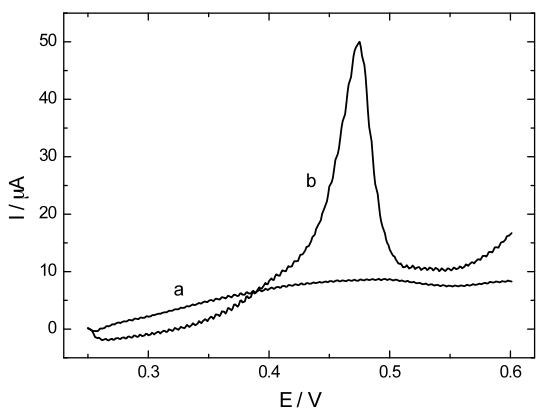

Fig. 4. The forward scans of voltammograms for DPPC desorption in the absence (a) and in the presence (b) of $5 \mathrm{mM} \mathrm{Ce}\left(\mathrm{SO}_{4}\right)_{2}$ in the aqueous phase, corrected for the base electrolyte current. Organic phase: $5 \mathrm{mM}$ TBACBB $+40 \mu \mathrm{M}$ DPPC. Aqueous phase: $0.7 \mathrm{M} \mathrm{H}_{2} \mathrm{SO}_{4}$. Area of the interface, $20 \mathrm{~mm}^{2}$. Polarization rate, $v=0.24 \mathrm{~V}$ $\mathrm{s}^{-1}$. The time of maintaining the initial potential, $E_{\mathrm{i}}=0.25 \mathrm{~V}$, was $90 \mathrm{~s} . \mathrm{CBB}^{-}$is the hexabromo derivative of the monocarborane $(7,8,9,10,11$, $\left.12-\mathrm{Br}_{6}-1-\mathrm{CB}_{11} \mathrm{H}_{6}\right)^{-}$.

We have shown that in the absence of the cerium salt the DPPC film is a monolayer [9]. The total desorption charge equals to $0.2 \mathrm{C} \mathrm{m}^{-2}$, which corresponds to the DPPC surface concentration of $2 \times 10^{-6} \mathrm{~mol} \mathrm{~m}^{-2}$. The charge passed during the DPPC layer decay in the presence of cerium sulfate is substantially higher (cf. curves $a$ and $b$ in Fig. 4). This indicates that a multilayer is formed, as also follows from the substantially longer time of the layer formation at the initial potential. A strong inhibitory effect of the DPPC layer has been observed in case of the transfer of $\mathrm{K}^{+}$facilitated by a crown ether, which can start only after the DPPC layer is destroyed [8]. Essentially, the transfer rate is limited by the slow transport of the crown ether through the DPPC layer from the organic to the aqueous phase, where the complex is formed, permitting the passage of $\mathrm{K}^{+}$into the organic phase. These results also support the conclusion that the $\mathrm{K}^{+}$-crown complex is formed on the aqueous side of the interface, like in case of the $\mathrm{Na}^{+}$-crown complex [10].

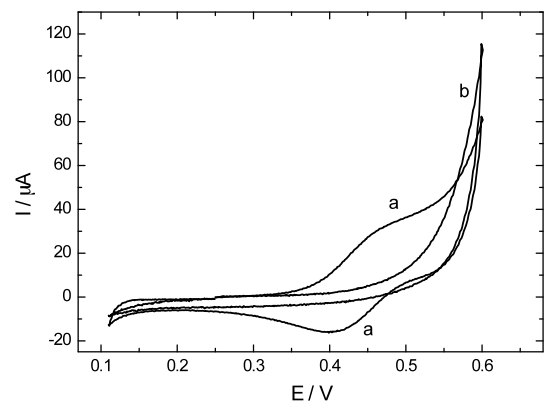

Fig. 5. Cyclic voltammograms recorded in the presence of $0.5 \mathrm{mM} \mathrm{TMACl}$ in the aqueous phase. Base electrolytes: $5 \mathrm{mM}$ TBACBB +1 $\mathrm{mM}$ TODATPB in 1,2-DCE; $0.01 \mathrm{M} \mathrm{Ce}(\mathrm{SO})_{4}+$ $0.01 \mathrm{M} \mathrm{LiCl}+1.5 \mathrm{M} \mathrm{H}_{2} \mathrm{SO}_{4}$ in water. The time of maintaining the initial potential $E_{\mathrm{i}}=0.25 \mathrm{~V}$ : (a) 0 , (b) $83 \mathrm{~min}$. Area of the interface, $26 \mathrm{~mm}^{2}$. Polarization rate, $v=0.06 \mathrm{~V} \mathrm{~s}^{-1}$. $\mathrm{CBB}^{-}$is the hexabromo derivative of the monocarborane $\left(7,8,9,10,11,12-\mathrm{Br}_{6}-1-\mathrm{CB}_{11} \mathrm{H}_{6}\right)^{-}$.

Similar inhibitory effect has been observed in measurements, which were carried out with TODA $^{+}$instead of DPPC (cf. Fig. 5). Specifically, the $\mathrm{TODA}^{+}$layer has been found to inhibit the transfer of $\mathrm{TMA}^{+}$from the aqueous to the organic solvent phase. Like in case of DPPC, the inhibition depends on the time delay at the initial potential, i.e., on the thickness of the $\mathrm{TODA}^{+}$ layer that is slowly formed. The observed effect also indicates that the $\mathrm{Ce}^{4+}$ cation under an excess of $\mathrm{H}_{2} \mathrm{SO}_{4}$ is present in the form of its anionic sulfate complex enabling an electrostatic 
stabilization of the adsorbed layer of the positively charged TODA ${ }^{+}$. It should be noted that these interactions are similar to those between $\mathrm{TODA}^{+}$and silicate ions observed with the alkaline aqueous electrolyte solutions $[5,6]$. In contrast, no such interactions has been found for the adsorbed DPPC in contact with the aqueous alkaline silicate solutions. Obviously, when DPPC is in the zwitterionic form, the ionic interactions are very weak, i.e., DPPC forms ion-pairs primarily in acidic media.

\section{Preparation of a polymer surface layer}

It has been shown that the adsorbed layers of surface active compounds dissolved in organic phase can be stabilized by a chemical reaction resulting in oxidation of the adsorbed monomers by a redox couple dissolved in water [11]. Oxidation of the adsorbed monomer leads to the formation of a compact polymer layer. Polymerization of the adsorbed monomers at the water/1,2-dichloroethane interface was studied using a series of the pyrrole derivatives. Several surface active pyrrole derivatives with one (Fig. 6) or two pyrrole units (Fig. 7) in the molecule differing in the alkyl chain length were synthesized $[11,12]$. Owing to a higher oxidation potential, the derivatives with one pyrrole unit in the molecule can be oxidized by a stronger oxidant like the aqueous $\mathrm{Ce}^{4+}$ cation [11, 13]. In contrast, the lower oxidation potential of the derivatives with two pyrrole units in the molecule makes it possible to use a weaker oxidant like the aqueous $\mathrm{Fe}^{3+}$ cation [12] The use of $\mathrm{Fe}^{3+}$ is more advantageous, because the solution acidity need not be as high as with $\mathrm{Ce}^{4+}$.

Formation of the polymer layer at the ITIES was monitored by the surface tension measurement at the polarized pendant aqueous electrolyte drop in the presence of transferable ions.

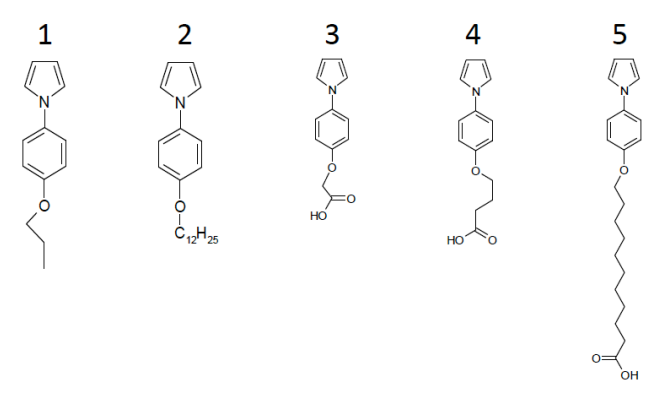

Fig. 6. Structure of monomers with one pyrrole unit in the molecule.
6

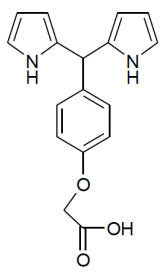

7

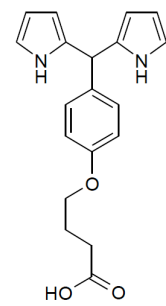

Fig. 7. Structure of monomers with two pyrrole units in the molecule.

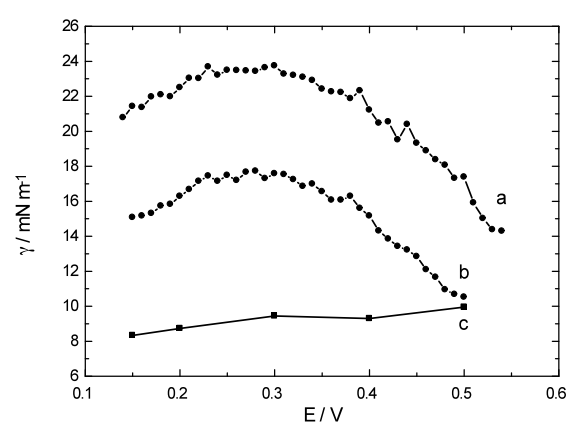

Fig. 8. Surface tension at the water|1,2-DCE interface in the presence of $1 \mathrm{mM}$ : (a) monomer $1,(b, c$,$) monomer 3$ in the organic phase. Curve c shows five measurements each after $17 \mathrm{~min}$ of the polymerization reaction with a new drop. Aqueous phase: $0.01 \mathrm{M} \mathrm{LiCl}, 1.5 \mathrm{M} \mathrm{H}_{2} \mathrm{SO}_{4}$, with (c) or without $(\mathrm{a}, \mathrm{b}) 0.01 \mathrm{M} \mathrm{Ce}\left(\mathrm{SO}_{4}\right)_{2}$. Organic phase: $5 \mathrm{mM}$ TBACBB, $1 \mathrm{mM}$ monomer. $\mathrm{CBB}^{-}$ is the hexabromo derivative of the monocarborane $\left(7,8,9,10,11,12-\mathrm{Br}_{6}-1-\mathrm{CB}_{11} \mathrm{H}_{6}\right)^{-}$. 
The effect of the applied potential on the surface tension in the presence of the monomers 1 and 3 is shown in Fig. 8, curves a and b. The decrease of the surface tension in the presence of the monomer 3 is larger (curve b) than in the presence of the monomer 1 (curve a). The surface activity of the monomer 3 is enhanced in alkaline solution due to the dissociation of proton from the carboxylic group displaying the effect of charge on the adsorption. The limiting surface concentration $\Gamma_{\mathrm{m}}=1.4 \times 10^{-6} \mathrm{~mol} \mathrm{~m}^{-2}$ at $E=0.15 \mathrm{~V}$ of the monomer 3 in an acidic solution was calculated from the adsorption data using the state equation based on a Langmuir-type expression [11].

A large effect on surface tension was observed upon an addition of $\mathrm{Ce}^{4+}$ to the aqueous phase in the presence of monomer 3 (Fig. 8, curve c), in which case the surface tension decreases and becomes independent of the applied potential. Consequently, the surface layer formed in the presence of $\mathrm{Ce}^{4+}$ is very stable and does not desorb at low potentials. Compression of the drop with the adsorbed layer leads to a typical, drop shape distortion, "a wrinkled skin", which does not vary with time. These results indicate that the surface layer formed in the presence of $\mathrm{Ce}^{4+}$ is not a simple adsorbed layer. Such behavior can be anticipated only when adsorbed molecules are bound together to some extent by the formation of a polymer layer. Surface tension in the presence of monomer 1 and 2 did not change significantly upon an addition of $\mathrm{Ce}^{4+}$ to the aqueous phase and exhibits the same potential dependence as in the absence of $\mathrm{Ce}^{4+}$ (Fig. 8, curve a). This indicates that the polymerization reaction does not proceed, probably due to the low surface concentration of monomers 1 and 2 in the adsorbed layer.

The transfer reaction of $\mathrm{K}^{+}$and $\mathrm{H}^{+}$facilitated by a crown ether (dibenzo-18-crown-6, DB18C6), and the transfer reaction of $\mathrm{TMA}^{+}, \mathrm{TEA}^{+}$ and $\mathrm{PF}_{6}{ }^{-}$were used to monitor formation of the polymer layer at the water/1,2-DCE interface.

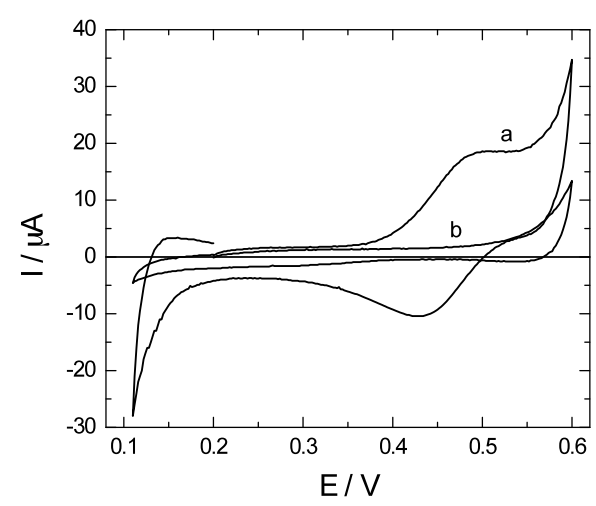

Fig. 9. Cyclic voltammograms of $\mathrm{TMA}^{+}$transfer across the water|1,2-DCE interface in the presence of monomer 3 in the organic phase and $\mathrm{Ce}^{4+}$ in the aqueous phase. Aqueous phase: 0.01 $\mathrm{M} \mathrm{LiCl}, 1.5 \mathrm{M} \mathrm{H}_{2} \mathrm{SO}_{4}, 0.01 \mathrm{M} \mathrm{Ce}\left(\mathrm{SO}_{4}\right)_{2}, 0.5$ mM TMACl. Organic phase: $5 \mathrm{mM}$ TBACBB, $0.94 \mathrm{mM}$ monomer 3. (a) the first and (b) the $18^{\text {th }}$ scan. Delay between scans $1 \mathrm{~min}$ at $0.35 \mathrm{~V}$. Polarization rate $0.1 \mathrm{~V} \mathrm{~s}^{-1}$. Area of the interface, $23.5 \mathrm{~mm}^{2}$. $\mathrm{CBB}^{-}$is the hexabromo derivative of the mono- carborane $\left(7,8,9,10,11,12-\mathrm{Br}_{6}-1\right.$ $\left.\mathrm{CB}_{11} \mathrm{H}_{6}\right)^{-}$.

The polymer layers prepared from the monomers 2-7 (Figs. 6, 7) strongly inhibits the simple ion transfer, as well as the facilitated $\mathrm{K}^{+}$ transfer reactions $[11,13]$. The cyclic voltammogram of the $\mathrm{TMA}^{+}$transfer across the water/ 1,2-DCE interface in the presence of the monomer 3 in the organic phase and cerium(IV) sulfate in the aqueous phase is shown in Fig. 9. The first scan (curve a, Fig. 9), recorded immediately after the filling the cell is the same as the reversible voltammogram recorded in the absence of $\mathrm{Ce}^{4+}$. With increasing the number of scans (recorded always after the 1 min delay), 
the potential difference of the forward and the reversed peaks increases and the peak currents decreases. Finally, almost no peak is observable on the $18^{\text {th }}$ scan (curve b).

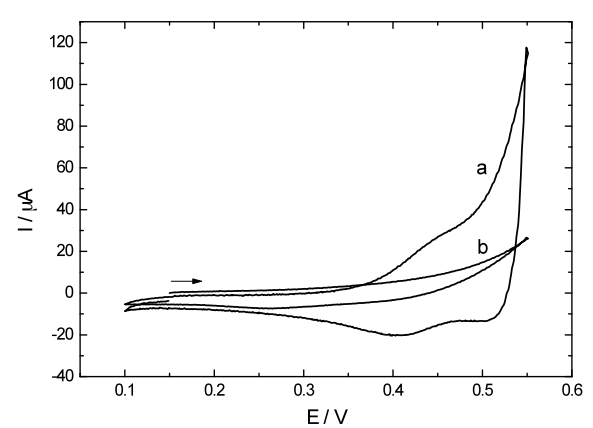

Fig. 10. Cyclic voltammograms of the $\mathrm{H}^{+}$ transfer across the water|1,2-DCE interface assisted by DB18C6 at the beginning (a) and at the end of the monomer 7 (b) polymerization. Aqueous phase: $0.1 \mathrm{M} \mathrm{HCl}+0.01 \mathrm{M} \mathrm{FeCl}_{3}$. Organic phase: $5 \mathrm{mM}$ TBACBB $+0.5 \mathrm{mM}$ $\mathrm{DB} 18 \mathrm{C} 6+1 \mathrm{mM}$ monomer. Scan rate $50 \mathrm{mV} \mathrm{s}^{-1}$. Area of the interface, $20 \mathrm{~mm}^{2}$. $\mathrm{CBB}^{-}$is the hexabromo derivative of the mono- carborane $\left(7,8,9,10,11,12-\mathrm{Br}_{6}-1-\mathrm{CB}_{11} \mathrm{H}_{6}\right)^{-}$.

The effect of the polymer layer prepared from the monomers 2-5, Fig. 6, on the transfer of $\mathrm{H}^{+}$facilitated by DB18C6 is negligible [11]. The current peaks of this facilitated transfer do not depend on the presence of $\mathrm{Ce}^{4+}$ in the aqueous phase. The facilitated transfer reactions proceed via the formation of a complex at the interface. Consequently, small pores filled with the aqueous phase in the polymer layer can be detected, if they are permeable for $\mathrm{H}^{+}$cations. In contrast, the polymer layers prepared from the monomers 6 and 7 (Fig. 7) [13] inhibit the proton transfer reaction assisted by DB18C6 (Fig. 10).

\section{Conclusions}

The polarized liquid/liquid interfaces offer a very promising environment for the production of the thin and porous membranes with well-defined and reproducible properties, which can be readily modified chemically. Such membranes can find applications in analytical and preparative chemistry, as well as in modeling of various transfer processes at biological membranes. Using this approach the membranes supported on solid porous materials could also be prepared for applications in separation technologies.

\section{Acknowledgement}

This work was supported by the Grant Agency of the Czech Republic (grant No. 13-04630S).

\section{References}

1. C. J. Brinker and G. W. Scherer, Sol-Gel Science, Academic Press, N.Y., 1990.

2. J. Kornatowski, Zeolites 8 (1988) 77.

3. O. Pachtová, M. Kočiřík, A. Zikánová, B. Bernauer, S. Miachon, J.-A. Dalmon, Micropor. Mesopor. Mater. 55 (2002) 285.

4. Z. Samec, T. Kakiuchi, in: Advances in Electrochemistry and Electrochemical Science (H. Gerischer, C. W. Tobias, eds.), Verlag Chemie, Weinheim, 1995.

5. V. Mareček, H. Jänchenová, J. Electroanal. Chem. 558 (2003) 119.

6. H. Jänchenová, K. Štulík, V. Mareček, J. Electroanal. Chem. 591 (2006) 41.

7. K. Maeda, Y. Yoshida, T. Goto, V. Mareček, J. Electroanal. Chem. 567 (2004) 317.

8. H. Jänchenová, K. Štulík, V. Mareček, J. Electroanal. Chem. 604 (2007) 109.

9. V. Mareček, A. Lhotský, H. Jänchenová, J. Phys. Chem. B, 107 (2003) 4573.

10. T. Kakutani, Y. Nishiwaki, T. Osakai and M. Senda, Bull. Chem. Soc. Jpn. 59 (1986) 781.

11. K. Maeda, H. Jänchenová, A. Lhotský, I. Stibor, J. Budka and V. Mareček, J. Electroanal. Chem. 516 (2001) 103.

12. V. Mareček, H. Jänchenová, I. Stibor, J. Budka, J. Electroanal. Chem. 575 (2005) 293.

13. K. Maeda, H. Jänchenová, A. Lhotský, I. Stibor, J. Budka and V. Mareček, Anal. Sci. 17 (2001) i325. 